\title{
A METHOD FOR THE LOCALIZATION AND PRODUCTION OF DISCRETE DESTRUCTIVE LESIONS IN BRAIN
}

\author{
BY
}

\author{
I. R. McCAUL
}

\section{From the Department of Neurosurgery, Whittington Hospital, London}

That the more distressing symptoms of Parkinsonism and other hyperkinetic disorders may be relieved surgically has now gained general acceptance. At the present time procedures in which destructive lesions, localized by a stereotactic method and made through a small cranial opening, have gained almost universal preference. It is proposed to describe such a technique. It has been found to work well in practice, disturbance to the patient is minimal, electro-physiological studies are facilitated since general anaesthesia is unnecessary, and the stereotactic instrument used is relatively inexpensive.

\section{Stereotaxis}

In practice, since most workers in the field of human stereotaxy use part of the visualized ventricular system as a reference point in localization
(Hankinson and Amador, 1956), the problem is reduced to the insertion of a cannula or electrode through the skull in the direction of an identical point plotted on two radiographs taken in planes at right angles to each other. The depth of insertion must also be known.

It has been found that a high degree of accuracy is obtainable by the use of a direction indicator so constructed that an adjustment in one plane can be made without altering the position in that at right angles to it.

\section{Description of Instrument}

The instrument (Fig. 1), made of stainless steel, consists of a ball drilled centrally and fitted to an electrode or cannula carrier (a). Into this carrier a directing rod (b) can be inserted. Two lead-containing markers (c) are fitted to the rod in such a way that the distance between

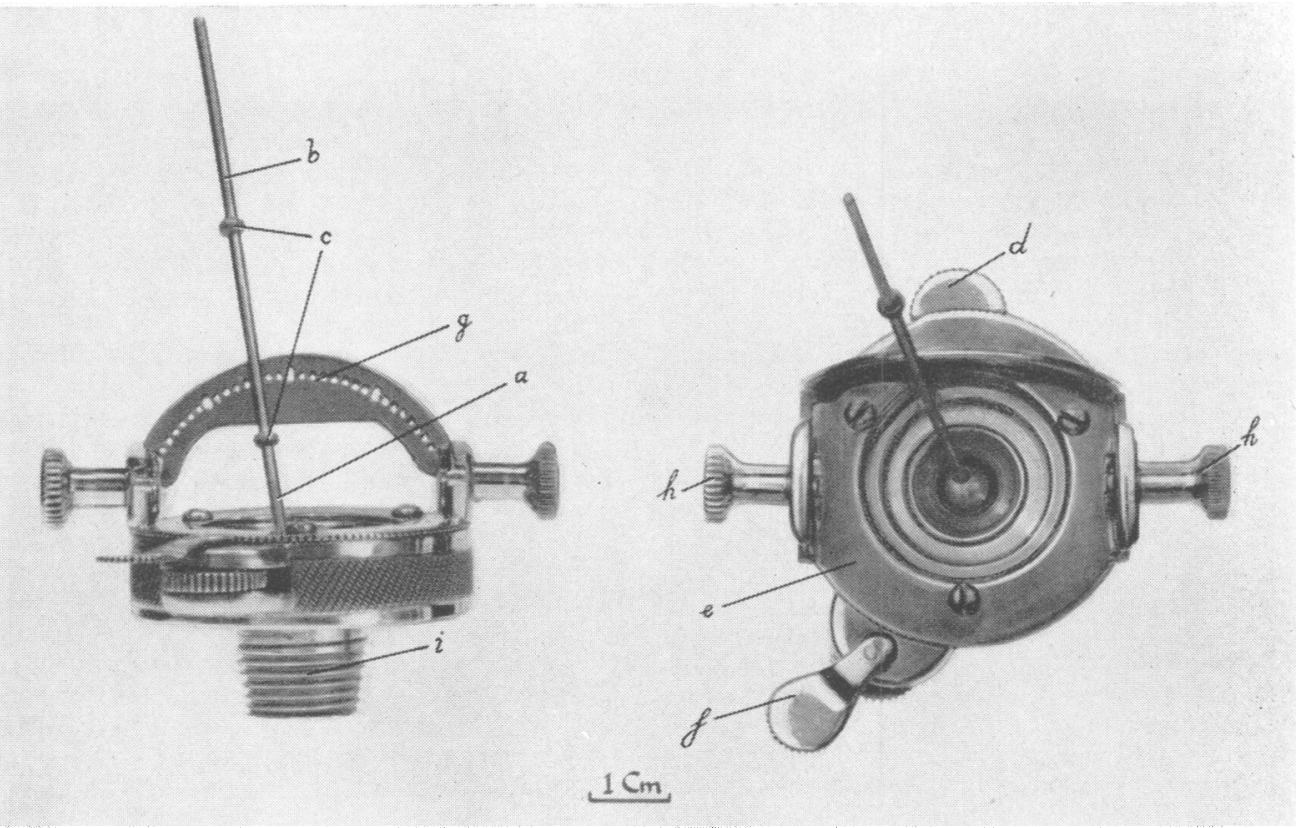

FIG. 1.-Stereotactic instrument. 
them is equal to that from the lower one to the centre of rotation of the ball. The ball may be locked in any desired position by means of the lever (d) and the mechanism is so designed that this action does not result in slight movement of the ball and carrier. A turntable (e) can be turned into any position, but when lever (f) is moved in a clockwise direction to the "on" position a "click" mechanism comes into play so that rotation through an angle of precisely $90^{\circ}$ may be appreciated by touch alone. On the turntable a curved perforated scale $(\mathrm{g})$ is mounted in such a way that it can be made to touch the directing rod. The centre of the circles formed by the arcs of the scale itself and the curved guides in which it runs is at the centre of rotation of the ball. The scale can be locked in any position by thumb screws (h). A lead strip is inserted between steel outer layers in the construction of the scale. Rigid fixation to the skull is obtained by the tapered tubular mounting (i) which has a screw thread and which fits the hole made by a $17 \mathrm{~mm}$. Hudson burr. The ball is situated in the lower part of the mounting.

\section{Method of Localization}

The conventional radiographic centring points are best discarded in favour of the nasion-inion line and one at right angles to it passing through two symmetrically placed points on the line $3 \mathrm{~cm}$. in front of the external auditory meatus. Radio-opaque markers are fixed to the scalp at all four points and a further marker is used to indicate the site of proposed insertion of the stereotactic instrument. The selection of this point is a matter of preference and has no bearing on the method of localization. When either the globus pallidus or thalamus has been the target a point about $4 \mathrm{~cm}$. from the mid-line near the coronal suture has been used.

All radiographic studies are made with a constant object-film and tube-film distance (F.F.D.). A skull stand of Schönander or Barazzetti type is an advantage but not a necessity. A F.F.D. of $90 \mathrm{~cm}$. or more is preferable.

Air is introduced into the ventricular system. Anteroposterior and lateral radiographs are taken and the target marked on each film. Superimposition of a brow-down and brow-up lateral projection may be necessary to define the position of the target if the posterior end of the third ventricle is required as a reference point. That the target marked on the two films represents an identical point within the skull may be checked since the vertical height of each point above the nasion-inion line should be the same.

The whole procedure is carried out under local anaesthesia and with the patient supine. Through a $3 \mathrm{~cm}$. incision at the point already determined, a burr hole is made in the skull using a $17 \mathrm{~mm}$. Hudson burr. The stereotactic instrument is then screwed home. The turntable is rotated until a "click" position is reached, the lever (f) moved to the "off" setting and the turntable again rotated until the curved perforated scale is lying parallel to the sagittal plane. The lever (f) is then moved to the "on" position and remains so throughout the rest of the procedure. The "click" device will now operate whenever the scale is moved through an angle of $90^{\circ}$.

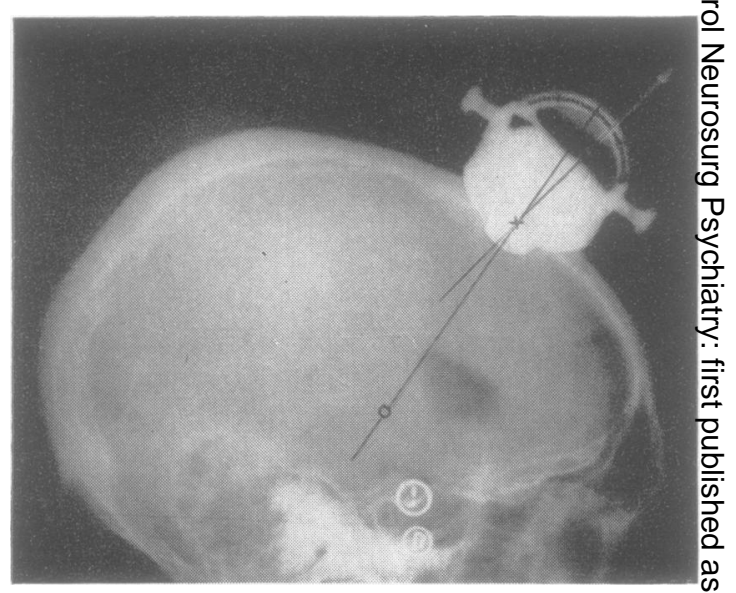

FIG. 2.-Line drawn from target through centre of rotation indicating correct position on scale.

The directing rod is next inserted into the carrier. The ball is freed by means of lever (d) and, aided by reference to the two films on which the target is marked, an attemp to estimate the correct line by eye is made. The ball i\$ then locked and the curved scale is moved against thi directing rod and a radiograph taken. The scale is thenmoved clear of the rod, rotated through an angle of 980 placed in contact with the rod again, and a furtiee radiograph taken in this plane. The films are then developed, fixed, and rapidly dried. If rinsed in $90 \%$ alcohol and then put between blotting paper they बrề ready in two minutes. A fine pencilled line is drawn each film extending the line of the directing rod towasds the cranial cavity. The distance on the films between the two markers on the rod is measured and a point of equab distance from the lower marker on the pencilled line then represents the centre of rotation of the ball. further pencilled line from the target through the centre of rotation and extended outwards to cross the perforate scale is drawn. The point on the scale in each projection at which the directing rod must be positioned to be correctly aimed at the target can now be seen (Fig. 2)윽 Care should be taken to ensure that the curved scale is, locked in a position touching the directing rod befor the latter is moved so that movement in only one plane at a time is possible.

The above procedure will only result in accurate alignment when the angle of correction necessary in the plane at right angles to that being corrected is less that about $10^{\circ}$. At angles greater than this the error due to radiographic distortion may become significant, the critical point depending on variations in F.F.D. (A) communication discussing this and other theoretica aspects of the method is in course of preparation b Dr. J. A. V. Bates.) The error, however, is never so great that by the above method a position within the $10 \mathrm{~N}$ margin will not be attained. At worst, therefore, further two films may be necessary before accurat 8 positioning of the carrier is achieved. In practice it is్ usual to obtain a satisfactory position after the first 


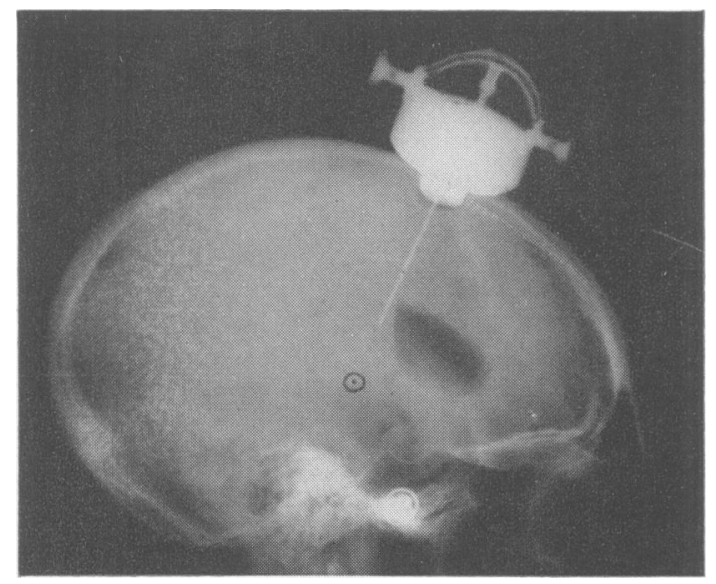

FIG. 3.-Calculation of depth.

two radiographs have been taken provided a reasonably careful alignment is made when initially positioning the directing rod.

\section{Calculation of Depth}

The distance from the upper end of the electrode or cannula carrier to the target, measured on a radiograph, represents the required depth modified not only by radiographic magnification but also by foreshortening due to angulation in the plane at right angles to that being examined. The actual depth is best calculated by insertion of a cannula of known length and this when measured on the radiograph enables the magnification factor to be determined. Greater accuracy is obtained by using a short-length of cannula near to the central $x$-ray beam (Bates, personal communication).

Since experience has shown that as far as the globus pallidus and thalamus are concerned, the actual depth is always more than $8 \mathrm{~cm}$., a cannula $8 \mathrm{~cm}$. long with a small hole drilled through it at right angles to its axis $2 \mathrm{~cm}$. from the distal end is inserted to its full extent into the carrier. The hole in the cannula can be seen radiographically and the distance on the film which represents an actual length of $2 \mathrm{~cm}$. measured (Fig. 3). If $x$ represents the true distance from the end of the $8 \mathrm{~cm}$. cannula to the target, a the length of the $2 \mathrm{~cm}$. segment when measured on the radiograph, and $b$ the distance from the end of the cannula to the target measured on the film, $x=\frac{2 b}{a}$. This therefore represents the value in centimetres which must be added to the $8 \mathrm{~cm}$. insertion in order that the tip of the cannula may coincide with the target.

\section{Making the Lesion}

The making of a focal coagulative lesion with diathermy current was initially tried but the technique was felt to be unreliable and was abandoned. A method of chemical coagulation (Cooper, 1955) using absolute alcohol had been described and this substance, coloured with dye, was injected into necropsy material. It was found that the fluid tended to take the line of least resistance running in the direction of main fibre tracts. About this time a further communication by the same author (Cooper, 1956) indicated that he was now increasing the viscosity of the injected fluid by the addition of ethocel. This mixture too was subjected to the same examination but again, in necropsy material at least, the degree of spread was found to be unpredictable. Further studies seemed to indicate that the chemical agent injected should be in the form of a thick paste. Kaolin powder was therefore added to the alcohol-ethocel solution ("etopalin") and it is this mixture which has been used during the past two years. No adverse effects have been attributed to its use. Since no patient has died, it

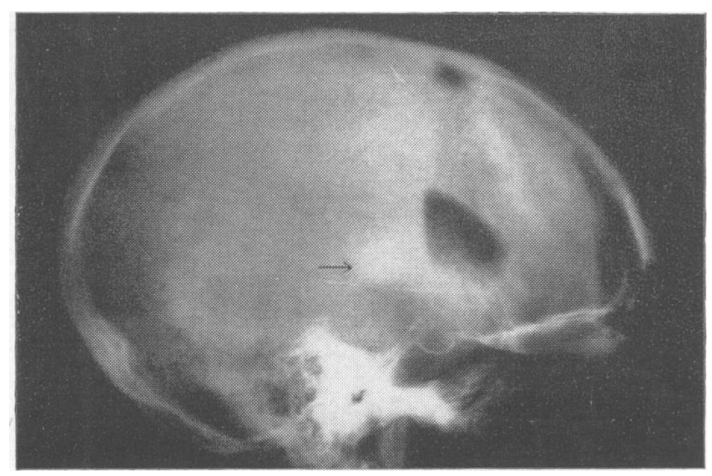

FIG. 4.-Post-operative film, showing outline of injected "alcohol paste".

remains to be established what part each constituent of the mixture plays in the making of a lesion which on clinical grounds appears to be satisfactory.

A cannula with a stop at the required distance is inserted into the instrument carrier. A No. 18 gauge spinal puncture needle with the bevelled point removed will be found to be satisfactory. One millilitre "hypaque" and $3 \mathrm{ml}$. "etopalin" are mixed together and kaolin powder sterilized by dry heat is added until a thick paste of the consistency of toothpaste (dentifrice) is obtained. The paste is inserted into the open barrel of a $20 \mathrm{ml}$. syringe, the plunger inserted, and the mixture injected into the open barrel of a narrow bore $1 \mathrm{ml}$. syringe. The type used for tuberculin testing will be found to meet all requirements. If the paste is made correctly it is not possible to fill the narrow bore syringe by drawing back the plunger in the usual manner. The syringe is attached to the cannula and the plunger depressed very slowly, the effect on tremor and muscle tone being constantly assessed. A second syringe must be used if more than $1 \mathrm{ml}$. of the material is required. In thalamic procedures a total of about $1 \mathrm{ml}$. is usually necessary (Fig. 4); for the globus pallidus slightly more. The paste sets hard at room temperature but is readily soluble in acetone.

Recurrence of significant tremor and rigidity is rare and a second injection at a later date is hardly ever necessary. 


\section{Summary}

A small, relatively light and inexpensive stereotactic instrument is described. An account of its use and the making of a localized destructive lesion in brain by the injection of "alcohol paste" is presented.

I am indebted to Messrs. K. O. Ford, the makers of the stereotactic instrument, for their most helpful cooperation during its development.
I am also indebted to Dr. A. K. Pittman, of Ciba Laboratories, for his help in making "etopalin" solution available.

\section{REFERENCES}

Bates, J. A. V. Personal communication.

Cooper, I. S. (1955). Science, 121, 217.

(1956). The Neurosurgical Alleviation of Parkinsonism. Charles

Hankinson, J. and Amador, L. V. (1956). Postgrad. med. J., 32, 28

\section{THE FEBRUARY (1959) ISSUE}

The February (1959) issue contains the following papers:-

A Clinical and Radiological Correlation of the Lesions Produced by Chemopallidectomy and Thalamectom

Gonzalo J. Bravo and Irving S. Cooper

Some Aspects of the Effects of Acute Reserpine Treatment on Behaviour. Peter H. Glow

Physiological Tremor in Children. John Marshall

The Mechanism of the Pain in Trigeminal Neuralgia. Eric Kugelberg and Ulf Lindblom

Lumbosacral Spina Bifida Cystica with Craniovertebral Anomalies: Report of Two Cases Presenting wittg

Neurological Disorder in Adult Life. John D. Spillane and Lambert Rogers

The Relief of Myotonia by the Use of a Potassium-binding Resin. Victor Tompkins, R. G. Lascelles, and $\overrightarrow{\overrightarrow{3}}$

Brian McKinney

The Estimation of Motility During Rest or Sleep. G. H. Cox and E. Marley

Blood Cerebrospinal Fluid Bromide Ratios in Mental Patients. A. J. Coppen

An Angiographic Test of Collateral Circulation through the Anterior Segment of the Circle of Willis. C. BO Sedzimir

The Application in General Medical Conditions of a Visual Method of Assessing and Representing Generalized

Electro-encephalographic Abnormalities. John Laidlaw

Proceedings of the Society of British Neurological Surgeons: 58th Meeting

Book Reviews

A number of copies are still available and may be obtained from the Publishing Manager, British

Medical Association, Tavistock Square, W.C.1, price 17s. $6 \mathrm{~d}$. 